\title{
A Cytological and Morphological Analysis of Tomato Species*
}

By

\section{M. Humphrey}

Recized February $17,{ }_{93} 6$

\section{Introduction}

The tomato has been included in the genus Solanum by some taxonomists and in the genus Lycopersicum by others. Engler and Prantl (8) use Solanum lycopersicum Mill. with Lycopersicum esculentum Mill. as a synonym. In 1788 Miller (16) named the cultivated tomato Lycopersicum esculentum and one of the wild forms L. pimpinellifolium.

Both Endlicher (7) and Bentham and Hooker (4) give Lycopersicum as the genus name for the tomato. There is still some disagreement as to which name should be used, but most botanists now use the genus name Lycopersicum. The species names given by Miller (16) are also used: esculentum for the cultivated species and pimpinellifolium for the wild one. The names racemigerum and racemiforme have been used as synonyms of pimpinellifolium.

Whether or not these species are well enough differentiated may be questioned by geneticists for they hybridize freely and their many morphological differences are demonstrably genetic. The geneticists' and taxonomists' conceptions of the meaning and scope of the word species often differ. The geneticist is not inclined to consider simple morphological differences as of sufficient importance to warrant the splitting off of new species, but would rather consider plants with such characters as genetic strains or varieties of one species.

When two so-called species are crossed with difficulty, and much meiotic irregularity occurs in the $\mathrm{F}_{1}$ with subsequent pollen sterility and a sharply reduced fertility, one is doubtless justified in considering them as separate species. But when two so-called species hybridize freely, as many do in nature, with subsequent complete fertility, and where the specific differences are small-such things as slight differences in pubescence, size of fruit, color of flower, or shape of anthers, and innumerable other such trifling differences that are due to demonstrable gene variations-there would seem to be no justification in considering them as separate species.

The classification of genus Lycopersicum may still be considered unsatisfactory because the species fall somewhere between the above

* Paper No. 71, Department of Genetics, Iowa State College. Partly aided by grant from Rockefeller Foundation. 
mentioned extremes. They differ in many morphological respects, though chiefly in the matter of size and habit of growth. Meiosis is nearly regular in the hybrid and while there is about 15 per cent pollen abortion, and fertility of the hybrid is somewhat reduced, they nevertheless still hybridize easily and are highly fertile. Rather than to consider them as two completely differentiated species it would be preferable to consider that esculentum is a species in the making and that evolution or domestication has not proceeded far enough as yet to have completed its separation into species fully removed from $L$. pimpinellifolium.

Merely for convenience, therefore, I shall speak of Lycopersicum esculentum and L. pimpinellifolium as though they were different species.

One of the chief reasons for making this investigation is that in the literature there exists so much confusion in the use of names L. esculentum, pimpinellifolium, racemiforme and racemigerum that the reader does not know whether the author is referring to one species or the other. We have available at Iowa State College material of both species from various parts of the world, and are in a good position to clarify the confusion.

\section{Material and Methods}

The material for this investigation comes from Dr. E. W. Lindstrom's tomato cultures. Those I have used are the diploid $L$. esculentum regenerated from the haploid (14) as well as numerous commercial varieties, and a pure strain of $L$. pimpinellifolium that has been carried on here for over 10 years; and the hybrid of these species. In addition to this material Dr. Lindstrom has secured the seed of small fruited tomatoes from the following locations: Germany, seed from Sengbusch; Lima, Peru, seed from Lesley; Peru seed from Vavilov; the Philippines, seed from Koert; Hawaii, seed from Collins; two locations in Guatemala, seed from Weatherwax; Florida, seed from Hull; and England, seed from Ashby. Some of these were sent as $L$. racemigerum, some as L. pimpinellifolium and some were merely called a wild tomato.

For a study of the somatic chromosomes root tips were removed from pot-bound plants and killed in a chromic, acetic, formalin fluid of the following formula: 1 per cent chromic acid 45 c.c., 1 per cent gl. acetic acid 45 c.c., 37 per cent Formalin U.S.P. 5 c.c. Killing and fixation is complete in 12 to 24 hours. Dehydration and clearing were accomplished rapidly in the following manner: 1 . transfer root tips to 70 per cent acetone, 2.80 per cent, 3 . 90 per cent, 4 . anhydrous acetone twice, 5 . one-fourth xylene to three-fourths acetone, 
6. one-half xylene to one-half acetone, 7. three-fourths xylene to onefourth acetone, 8. pure xylene twice, then inbed in paraffin in the usual manner. The interval between changes of fluids during dehydration and clearing may be from 15 minutes to whatever is convenient, but material may be rapidly run up with this schedule and is every bit as satisfactory as when done by much slower methods. Sections were cut at 12 microns and stained with iodine-violet.

Most of the meiotic material was studied from aceto-carmine preparations though a little was prepared in the same manner as the root tips except that iron alum-hematoxylin stain was used. The aceto-carmine method is more satisfactory because flatter preparations are possible. It was thought advisable to study the relative sizes of the stomata and for this study fresh leaves were used without treatment. The sizes were measured in microns with the aid of a camera lucida.

The pollen measurements were also made from fresh material. Pollen was shaken into a drop of aceto-carmine, and its diameter measured in the same manner used with the stomata.

\section{Description of the Species}

In order that there shall be no question of what morphologically differentiates the two tomato species I shall give verbatim the description of the genus from Bailey's Manual of Cultivated Plants (2). The nomenclature, except as explained in the introduction agrees with the majority of the taxonomic works. The description follows: "1. L. esculentum, Mill. Spreading hairy-pubescent and more or less glandular strong-smelling plur-annual or perennial, 3-6 feet or more, the young growth on mature plants erect; leaves odd-pinnate with small leaflets interposed, 6-18 inches long; main leaflets 5-9, stalked, ovate to oblong, 2-3 inches long, acuminate, irregularly toothed, margins tending to roll inward: flowers $3-7$, nodding, $3 / 4$ inch or more across, on jointed pedicels: fruit red or yellow, usually flattened at the ends, 2-3 inches across, the sides furrowed or angled. W. S. America; now little known in cultivation in this country. Var. cerasiforme, Alef. Cherry Tomato. Leaves thinner and mostly smaller and usually less acuminate: flowers prevailingly in longer clusters : fruit globular and regular, about $3 / 4$ inch in diameter, red or yellow, few-celled; forms with oblong fruit are the plum tomatoes. Var. pyriforme Alef. Pear Tomato, differs in bearing pear-shaped fruits, which are usually about $11 / 2$ inches long. Var. commune Bailey, (var. vulgare, Bailey, not Alef.). Common Tomato. Leaflets little if at all conduplicate or curled, the plants heavier and more lopping; fruit mostly globular or only moderately oblate not furrowed or lobed on the sides; 
parts of the flower often multiplied, the cells becoming many. Cultigen.* Var. grandifolium, Bailey. Large-leaved or PotatoLeaved Tomato. Leaves large and plane; leaflets usually not more than 5, large, with entire margins, the secondary leaflets few or none. Cultigen. Var. validum, Bailey. Upright Tomato. Plant stout and erect, very compact, the leaves crowded and curled. Cultigen; little grown in this country.

"2. L. pimpinellifolium Mill. " $L$. racemiforme and $L$. racemigérum, Lange). Currant Tomato. Weak, slender-stemed, not hairy but finely puberulent, the odor not pronounced: leaflets 5-7 with smaller ones interposed, long-stalked, ovate, $3 / 4-11 / 2$ inches long, pointed or obtuse, base sometimes cordate: flowers 10-25 in an elongating 2 -sided raceme, the pedicels prominently geniculate: fruits red, currant-like, about $1 / 2$ inch in diameter, 2-celled. Peru."

To the description of $L$. pimpinellifolium it might be well to add the following characteristics: Flower diameter $5 / 8$ inch, plant profusely branching and spreading, fruits $1 / 4$ to $1 / 2$ inch in diameter, raceme containing 10 to many fruits.

\section{Cytology of $L$. esculentum}

Afify (1) described the cytology of $L$. escuicntum and his form of $L$. racemigerum and reported no difference between the two either in behavior or chromosome morphology. The somatic chromosomes of our diploid esculentum from the haploid are essentially as Afify reported except that trabants were only present as minute knobs on the end of the chromosome, and the constrictions were much less pronounced (Fig. 1). The usual complement of 24 chromosomes was present, and in addition to observing their morphology the total length and volume of the 24 chromosomes were measured. In this pure esculentum the total length of the chromosomes was 41.9 microns and the total volume was 36.6 cubic microns. These figures will be useful later in comparing this species with L. pimpinellifolium. The somatic chromosomes of $L$. racemigerum from England, which is the same material as was used by Afify, were identical, both as to size and morphology, with our diploid esculentum from the haploid (Fig. 13).

Meiosis in the diploid esculentum has been previously reported by several workers as well as by the author (9) in considerable detail. It is also discussed by Afify (1) who includes a discussion of chiasma formation. The pachytene threads are too small to show any great detail, especially as to the actual formation of chiasmata. We may

$*$ Cultigen $=$ Found only in cultivation. 

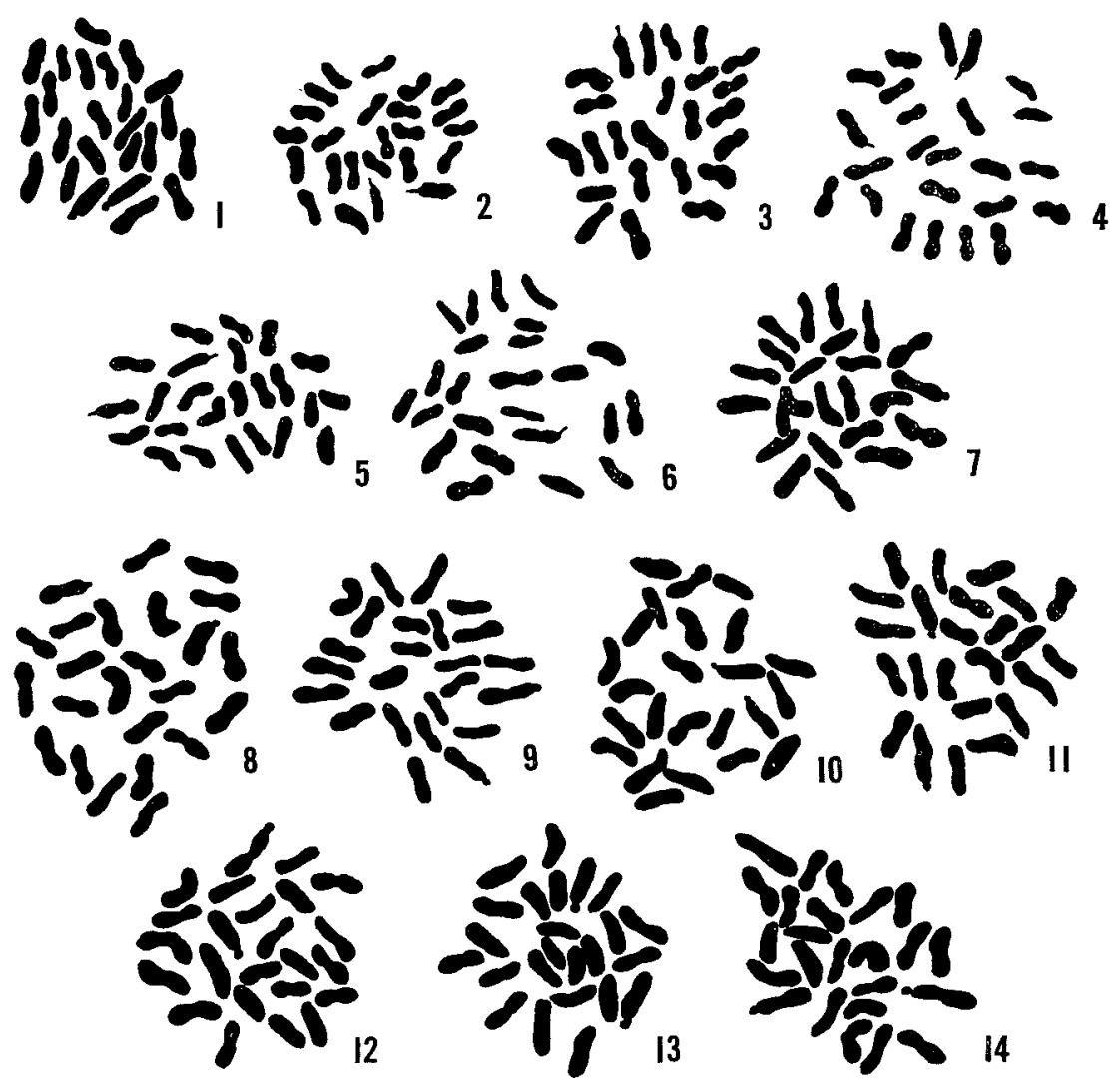

Figs. 1-14. Somatic chromosomes. 1. L. esculentum, diploid from haploid. $\quad 2 . \quad L$. pimpinellifolium. 3. $\mathrm{F}_{1}$ species hybrid. 4. L. racemigerum from Germany. 5. L. pimpinellifolium from Lima, Peru. 6. L. pimpinellifolium from Lima, Peru. 7. L. esculentum from the Philippines. 8. L. esculentum from Hawaii. 9. $L$. esculentum from Mulua, Guatemala. 10. L. esculentum from Guatemala City. 11. L. esculentum from Florida. 12. L. esculentum, red cherry variety. $13 . \quad$ L. racemigerum (esculentum) from England. 14. L. esculentum (yellow cherry) from Ames. $\times 3200$

probably safely assume that they arise as has been described by Belling (3). In various liliaceous plants where the pachytene threads are large enough to show the details of chiasma formation it is observed that half twists occur in the thread prior to the secondary split. Following the secondary split new fibers are formed between the new parts of the unlike but homologous chromosomes thus causing an exchange of partners at such a point but without causing an actual break and reconnection of parts of chromatids. Many such chiasmata may arise but relatively few remain until diplotene. Many will be compensating and some of the twists seen at pachytene may not form chiasmata. These will disappear at the earliest diplotene. Such details as these cannot be observed in the tomato 
but the chiasmata remaining at diplotene may be observed. The appearance of the diplotene chromosomes is shown in figure 15 . There is evidence of nearly complete terminalization of all chiasmata by diakinesis (Fig. 22). Usually only one or two bivalents retain one chiasma. It seems unlikely that terminal attachments should be considered chiasmata. If they are truly terminal they could not be chiasmata, for they will disappear as soon as terminalized. Sax and Humphrey (17) found in Tradescantia that in bivalents with terminal attachments there was not only no evidence of the presence of a chiasma in the chromonemata, but also no physical connection between the chromonemata. The terminal attachment would seem to be only between the pelicles of the two chromosomes. That the same relation holds in tomatoes cannot be stated with certainty, but it seems likely that the behavior would parallel that of Tradescantia. On this basis I would rather assume that in the shortest chromosomes there are from 0 to 1 chiasmata, and in the longest from 2 to 4 at diplotene; and at diakinesis there is at most one chiasma in one or two of the bivalents and none in the rest, the homologues being held together by terminal attachments of the type known to exist in Tradescantia.

At metaphase I (Fig. 23) the chromosomes are essentially spherical and have an average diameter of 1.1 microns. Subsequent meiotic stages have been previously described by Winkler (18), Lesley (12), Lindstrom and Koos (14), Humphrey (10), and Afify (1) and need no further description here.

\section{L. pimpinellifolium}

The somatic chromosomes of $L$. pimpinellifolium were similar to those of esculentum except that a very minute trabant was present and the chromosomes are distinctly smaller than those of esculentum (Fig. 2). The total length of the 24 chromosomes was only 35.4 microns, and the total vloume 28.2 cubic microns. These figures should be contrasted with 41.9 microns and 35.6 cubic microns for esculentum. If $L$. esculentum be taken as 100 per cent we find that the total length of the $L$. pimpinellifolium chromosomes is 84.7 per cent and the total volume 75.5 per cent. Such a size difference is obviously significant.

Meiosis in L. pimpinellifolium is essentially the same as in esculentum except that at diplotene there are approximately seven chiasmata and fewer at all times than in esculentum. (Fig. 16). At late diakinesis there are rarely any left and ring bivalents are almost never found (Fig. 24). The homologues are attached at one end only, in the form of rod bivalents, probably by a terminal pellicle attach- 
ment. Reduced chiasma number is presumably due to the smaller size of these chromosomes, although no difference could be observed between the lengths of pachytene chromosomes of the two species. In both cases they range from about 8 to 13 microns long. The diameter of the metaphase chromosomes is approximately 0.8 microns (Fig. 25); 0.3 micron less than in esculentum (6). Subsequent meiotic stages are similar to those in $L$. esculentum.

In order that a comparison may be made more easily between the two-species and between these and the various small fruited cultures they were all arranged in table form. I have placed the cultures in table 1 in such order that those which were morphologically pimpineliffolium are first; followed by those which were morphologically esculentum. Number 1 is our own strain of $L$. pimpinellifolium used for comparative purposes. The next three are also pimpineliffolium, from the sources indicated in the table. Number 5 is the diploid esculentum from the haploid also used for comparative purposes. The next seven cultures were received as small fruited tomatoes the species not having been designated with the exception of number 12, L. racemigerum from Ashby, this being the form used by the John Innes investigators. Number 13 is the species hybrid.

In the table are listed seven micromorphological measurements and four measurements of flower characters. In cultures 1 and 5, pure pimpinellifolium and esculentum respectively, the following differences were found: pollen diameter 21.6 and 25.7 microns, $M_{I}$ chromosome diameter 0.8 and 1.1 microns, total length of somatic chromosomes 35.4 and 41.9 microns, total volume of somatic chromosomes 28.3 and 35.6 cubic microns, diameter of -somatic nuclei 6.6 and 9.1 microns, cell volume approximately 7000 and 18000 cubic microns, and stoma size $26.6 \times 9$ and $32 \times 11$ microns. All of these sizes are very constant with the exception of cell volume. There is so much difference in cell size in different parts of the root that it is impossible to make an exact comparison. However, the above measurements were made from cells as nearly comparable as possible and even were the difference much less than it is the differences would appear very significant.

Among the flower characters the differences between the two species are somewhat less striking than in the micromorphological measurements but still constantly different. Flower diameter varies from $17 \mathrm{~mm}$. for pimpineliifolium to $22 \mathrm{~mm}$. for esculentum, length of sepal from 4 to $7 \mathrm{~mm}$., petal width from 1.8 to $4 \mathrm{~mm}$., and anther length from 5 to $7 \mathrm{~m} . \mathrm{m}$. The number of petals and sepals is constantly five in L. pimpinellifolium, but is usually six or seven 
in $L$. esculentum, although it is somewhat variable. However, there are rarely only five petals and five sepals in esculentum. It is also noteworthy that the locule number is increased from two in pimpinellifoitum to a variable number in esculentum.

Examination of the remaining cultures in the table will show that numbers 2,3 and 4 which were morphologically $L$. pimpinellifolium have, with small variations, measurements that fit this species (Figs. 4, 5, 6), and that the cultures from number 6 to 13 inclusive which were morphologically $L$. esculentum have measurements very closely comparable to number 5 , the pure diploid esculentum. (Figs. 7-14).

\section{Cytology of the Hybrid}

The size of the somatic chromosomes is somewhat intermediate between the two parent species but is nearer that of pimpinellifolium than esculentum (Fig. 3). The only pair of chromosomes that can be recognized is that with the minute projections. In esculentum it is only a very small knob on the end of the chromosome, and in pimpinellifolium the projection has the form of a very minute trabant, extending farther from the chromosome than in esculentum. No other pair of chromosomes could be positively identified.
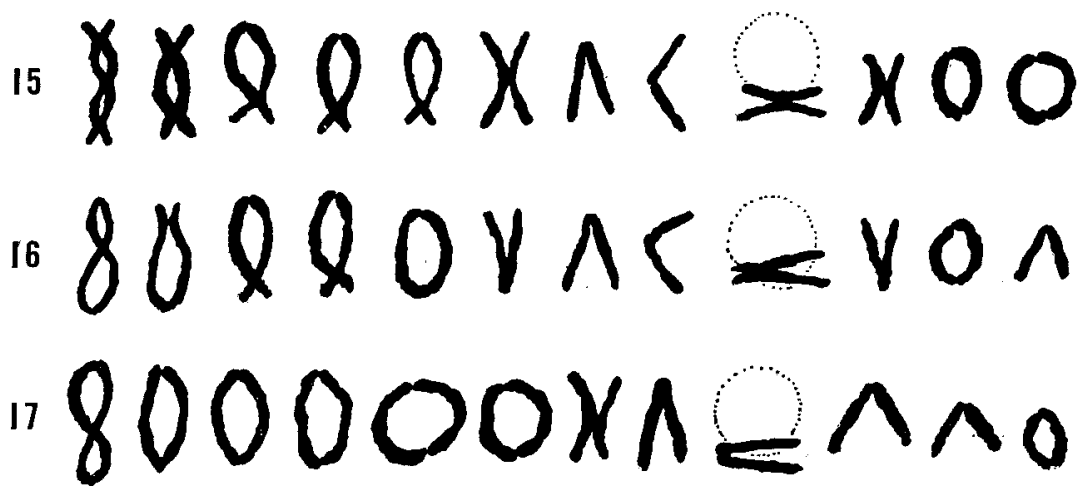

Figs. 15-17. Diplotene. 15. L. esculentum (diploid from haploid). 16. L. pimpinellifolium. 17. $\mathrm{F}_{1}$ hybrid. $\times 2600$

Meiosis in the hybrid is essentially regular except for a few irregularities which would indicate that there are some fundamental differences between the two species. In the pachytene of the two parents the chromosomes are synapsed throughout and they appear as single somewhat beaded threads (Fig. 18). Most of the pachytene chromosomes of the hybrid have this same appearance but there are a few regular and uniform exceptions in which certain parts of the pair of homologues do not synapse. The three chromosomes shown in figures 19, 20 and 21 are found in every cell at pachytene and 
in addition there are a few smaller loops to be seen part of the time, but how constantly these are present could not be determined. At diplotene, where the greatest number of chiasmata were to be seen in the two parent species, there were usually six rings with terminal attachments only, one figure eight and one cross with one chiasma each and four V-shaped bivalents with one terminal attachment and possibly one subterminal chiasma in one of them. This would make three and possibly occasionally four chiasmata (Fig. 17). There were doubtless more chiasmata at the beginning of diplotene but this stage could not be found, and even by the early diplotene stages in figure 17 the chiasmata had all been terminalised or compensated except three and sometimes four. This would indicate a sharp reduction in the number of chiasmata in the hybrid from that in either species.

At diakinesis the attachments are always at one end except in two and occasionally three of the bivalents which are always in the form of rings with very loose terminal attachments but no chiasmata

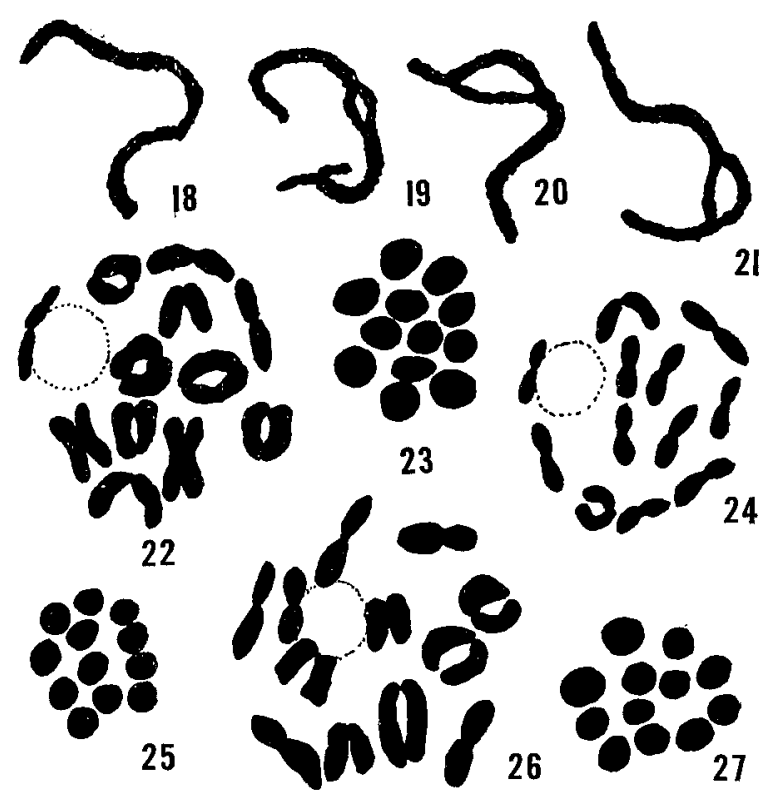

Figs. 18-21. Pacbytene in the hybrid. Figs. 22-23. Diakinesis and metaphase I in L. esculentum. Figs. 24-25. Diakinesis and metaphase $\mathrm{I}$ in $L$. pimpinellifolium. Figs. 26-27. Diakinesis and metaphase in the hybrid. $\times 3200$
(Fig. 26). The members of some of the bivalents are frequently so loosely associated that they have the appearance of univalents, though there probably always remains some connection between them for univalents are not seen at metaphase. At diakinesis a size difference may be observed between the members of certain pairs (Fig. 26) while in others none is apparent. This is sufficient evidence that allosyndesis has occurred, and not autosyndesis. From $\mathbf{M}_{\mathbf{I}}$ (Fig. 27) on, the behavior is normal and, although lagging might be expected to occur occasionally, there is no more in the hybrid than in the present species and behavior is exceedingly regular. 


\section{Discussion}

Afify (1) found no difference in behavior or chromosome morphology between the two species, $L$. esculentum and $L$. racemigerum, nor between these and their hybrid. Chiasma frequency seemed to be about the same in both species and the hybrid. In my material the results were quite different, and the differences probably trace to the fact that Afify's racemigerum is not in the pimpinellifolium group. The chromosomes of $L$. pimpinelififolium are distinctly smaller than those of escuientum. This is shown by the measurements of both somatic and meiotic chromosomes. Meiotic behavior is much the same in both species and is entirely regular. However, it is evident both from diplotene and diakinesis figures that there are fewer chiasmata in pimpinellifolium than in esculentum (Figs. 15, 16). At diplotene there are about eleven chiasmata in esculentum and seven in pimpinellifolium, while in the hybrid there are not more than four. These figures disregard terminal attachments which I do not consider true chiasmata for reasons explained above.

It has been observed that in a few plants, particularly corn, that a certain chromosome is always associated with the nucleolus. In the tomato a chromosome of certain shape is always seen to be associated with the nucleolus. This is true of both species and the hybrid. In the parent species there is one chiasma in this chromosome, but probably none in the hybrid (Figs. 22, 24, 26).

The phenomenon of secondary association or pairing of the chromosomes has been studied in considerable detail by Darlington, Lawrence and others, and is thought to be useful in determining basic chromosome numbers. Little significance has been attached to this phenomenon in the tomato. This type of association, first reported by Darlington in 1928 (5) and Lawrence (11) occurs only during first and second metaphase. It is thought to be an indication of a relationship between certain chromosomes and to indicate a lower basic number than appears to be present. It is occasionally observed in the tomato that some of the chromosomes happen to lie close together in the plate at second metaphase. This has been observed in the pseudometaphase of the haploid, in diploids of both species and their hybrid and in tetraploils of all of these. However, such pairing is often absent and is extremely variable and inconsistent, and furthermore in the tetraploid regenerated through the diploid from the haploid, in which there are 12 sets of exactly similar chromosomes, secondary pairing is no more consistent than in any other tetraploid or diploid. If secondary pairing be a significant phenomenon it should occur constantly in the tetraploid from the haploid. This, 
Table 1. Micromor-

\begin{tabular}{|c|c|c|c|c|c|}
\hline & \multirow[b]{2}{*}{ Culture } & \multirow[b]{2}{*}{ Donor of seed } & \multirow[b]{2}{*}{$\begin{array}{l}\text { Locality of } \\
\text { original plants }\end{array}$} & \multicolumn{2}{|c|}{ Meiotic* } \\
\hline & & & & $\begin{array}{l}\text { Pollen } \\
\text { diam. }\end{array}$ & $\begin{array}{c}\mathrm{IV}_{\mathrm{I}} \\
\text { chro- } \\
\text { mosome } \\
\text { diam. }\end{array}$ \\
\hline $\begin{array}{r}1 \\
2 \\
3 \\
4 \\
5 \\
6 \\
7 \\
8 \\
9 \\
10 \\
11 \\
12 \\
13\end{array}$ & $\begin{array}{l}\text { L. pimpinellifolium } \\
\text { Solanum racemigerum } \\
\text { Wild tomato } \\
\text { Wild tomato } \\
\text { Pure L. esculentum } \\
\text { Small-fruited tomato } \\
\text { Small-fruited tomato } \\
\text { Wild tomato } \\
\text { Wild tomato } \\
\text { Wild tomato } \\
\text { Yellow Cherry } \\
\text { L. racemigerum } \\
\text { L. pimpinellifolium } \\
\quad \times L \text {. esculentum } \mathrm{F}_{1}\end{array}$ & $\begin{array}{l}\text { E. W. Lindstrom } \\
\text { R. Sengbusch } \\
\text { J. W. Lesley } \\
\text { N. I. Vavilov } \\
\text { E. W. Lindstrom } \\
\text { E. H. Koert } \\
\text { J. L. Collins } \\
\text { Paul Weatherwax } \\
\text { Paul Weatherwax } \\
\text { E. H. Hull } \\
\text { E. W. Lindstrom } \\
\text { Eric Ashby } \\
\text { E. W. Lindstrom }\end{array}$ & $\begin{array}{l}\text { Ames } \\
\text { Germany } \\
\text { Lima, Peru } \\
\text { Peru } \\
\text { Ames } \\
\text { Philippines } \\
\text { Hawaii } \\
\text { Mulua, Gua temala } \\
\text { Guatemala City } \\
\text { Florida } \\
\text { Ames } \\
\text { England } \\
\text { Ames }\end{array}$ & $\begin{array}{l}21.6 \\
21.6 \\
21.7 \\
21.5 \\
25.7 \\
25.9 \\
25.4 \\
25.3 \\
26.0 \\
25.7 \\
25.5 \\
26.2 \\
23.38\end{array}$ & $\begin{array}{l}0.8 \\
0.8 \\
0.9 \\
0.8 \\
1.1 \\
1.1 \\
1.1 \\
1.05 \\
1.1 \\
1.2 \\
1.1 \\
1.1+ \\
1.0\end{array}$ \\
\hline
\end{tabular}

however, is not the case. Consequently we have not considered it of any significance, at least in the tomato, and have not mentioned it in previous papers.

It is evident from the data presented in the table, as well as from Bailey's description that there are many differences between the two tomato species. These differences are chiefly differences in size of various parts not only in such things as stems, leaves, fruits, etc., but in such small things as size of pollen, cell size, and even chromosome size. Afify found no difference whatever between the cytological features of esculentum and his racemigerum. The explanation for this would seem to be simply the fact that $L$. racemigerum which Afify was using was not L. pimpinellifolium, but a small-fruited esculentum. The seed sent to us by Ashby is presumably of the same stock as that used by Afify, and morphologically and cytologically it has all the characteristics of L. esculentum. Lycopersicum pimpinellifolium (racemigerum, racemiforme) may be easily recognized by the following morphological characteristics. It does not have pubescence on stems or leaves; leaves are smaller, lighter green and never rugose under normal conditions; stems are more slender and branch much more profusely than those of esculentum; the flowers are distinctly smaller in all their parts, and fruits are always smaller than the smallest-fruited esculentum. If there is still doubt in the mind of the investigator, the size of the pollen is a good constant indication, and rather more difficult to obtain are the sizes and volumes of cells, nuclei and chromosomes, all of which are good diagnostic characters for the two species. 
phological Characters

\begin{tabular}{|c|c|c|c|c|c|c|c|c|}
\hline \multicolumn{5}{|c|}{ Somatic } & \multicolumn{4}{|c|}{ Flower characters* } \\
\hline $\begin{array}{c}\text { 'Lotal } \\
\text { length of } \\
\text { chromo- } \\
\text { some }\end{array}$ & \begin{tabular}{|c|} 
Total \\
volume of \\
chromo- \\
somes
\end{tabular} & $\begin{array}{c}\text { Nucleus } \\
\text { diam. }\end{array}$ & $\begin{array}{c}\text { Cell } \\
\text { volume }\end{array}$ & $\begin{array}{l}\text { Stoma } \\
\text { size }\end{array}$ & $\begin{array}{c}\text { Flower } \\
\text { diam. }\end{array}$ & $\left|\begin{array}{c}\text { Length } \\
\text { of } \\
\text { sepal }\end{array}\right|$ & $\begin{array}{l}\text { Petal } \\
\text { width }\end{array}$ & $\begin{array}{l}\text { Anther } \\
\text { length }\end{array}$ \\
\hline $\begin{array}{l}35.4 \\
35.8 \\
35.3 \\
35.7 \\
41.9 \\
40.8 \\
42.2 \\
40.6 \\
41.4 \\
41.0 \\
41.1 \\
43.6\end{array}$ & $\begin{array}{l}28.3 \\
28.6 \\
28.2 \\
28.6 \\
35.6 \\
36.9 \\
37.3 \\
35.7 \\
36.4 \\
36.0 \\
36.1 \\
38.4\end{array}$ & $\begin{array}{l}6.6 \\
6.6 \\
6.6 \\
6.6 \\
9.1 \\
8.8 \\
8.9 \\
9.2 \\
9.0 \\
9.1 \\
8.8 \\
8.7\end{array}$ & $\begin{array}{r}7,028 \\
7,136 \\
7,310 \\
18,080 \\
19,386 \\
20,348 \\
18,926 \\
19,734 \\
21,102 \\
18,391 \\
21,600\end{array}$ & $\begin{array}{l}26.6 \times 9 \\
26.7 \times 9 \\
26.5 \times 9.1 \\
26.8 \times 9 \\
32 \times 11 \\
32 \times 11 \\
32.1 \times 11.1 \\
31.6 \times 11 \\
31.4 \times 11.6 \\
31.3 \times 11.5 \\
31.6 \times 11.2 \\
30 \times 12\end{array}$ & $\begin{array}{l}17 \\
17.5 \\
17 \\
18 \\
22 \\
21 \\
21 \\
21.5 \\
22 \\
22 \\
21 \\
20\end{array}$ & $\begin{array}{l}4 \\
3 \\
3.5 \\
4.5 \\
7 \\
6.5 \\
6.5 \\
7 \\
6 \\
6.5 \\
7.5 \\
6\end{array}$ & $\begin{array}{l}1.8 \\
1.5 \\
1.5 \\
2 \\
4 \\
4.5 \\
4.5 \\
4 \\
4.5 \\
4 \\
4 \\
3\end{array}$ & $\begin{array}{l}5 \\
5 \\
5 \\
5.5 \\
7 \\
6.5 \\
6 \\
7 \\
6.5 \\
7 \\
6.5 \\
6.5\end{array}$ \\
\hline 37.7 & 31.2 & 8.0 & 11,000 & & 18 & 5 & 2.5 & 6 \\
\hline
\end{tabular}

The characteristics of the hybrid, while somewhat intermediate are much closer to the pimpinellifolium type than the esculentum. Lindstrom (13) has shown that all genetic characters studied are highly dominant in pimpinellifolium. The $\mathrm{F}_{1}$ looks very much like the wild parent. The same tendency is also observed in the micromorphological characteristics, indicating a probable genetic control of such characters as well as the larger ones.

\section{Summary}

1. The cytology and micromorphology of Lycopersicum esculentum and L. pimpinellifolium and their hybrid were studied. A comparative study was also made of 10 small-fruited cultures from various parts of the world.

2. Chromosome behavior in both species was normal. $L$. pimpinellifolium had somewhat fewer chiasmata than esculentum.

3 . The hybrid was cytologically regular except for certain constant weaknesses of pairing at pachytene and a much reduced chiasma number throughout.

4. In the following micromorphological characters pimpinellifolium was significantly smaller: pollen size, chromosome size and volume, both somatic and meiotic, size of cell and nucleus in root tips, and size of stoma.

5. Flower parts are constantly five in pimpinellifolium. In esculentum they are variable but usually six or seven.

6. Three of the 11 cultures from foreign locations were true L. pimpinellifolium; the rest were small-fruited L. esculentum.

7. Secondary association is considered of no significance in the tomato. 
I wish to express my gratitude to Dr. E. W. Lindstrom, head of the Department of Genetics at Iowa State College, for the use of his tomato cultures and for his advise and helpful criticism in the performance of this investigation.

\section{Literature Cited}

1. Affy, A, 1933. The cytology of the hybrid between Lycopersicum esculentum and $L$. racemigerum in relation to its parents. Genetica $15: 226-210$.

2. Bailey, L. H. 1925. Manual of cultivated plants. Macmillan, New York.

3. Belling, J. 1933. Crossing over and gene rearrangement in flowering plants. Genetics 18: $370-413$.

4. Bentham. G. and Hooker, J. D. 1876. Genera Plantarum. 2:888. London

5. Darlington, C. D. 1928. Studies in Prunus. I and II. J. Genetics 19:213-256.

6. - 1932. Recent advances in Cytology. Blakiston, Philadelphia.

7. Endlicher, S. 1836. Genera Plantarum.

8. Engler, A. and Prantl, K. 1897. Die natürlichen Pflanzenfamilien. V. 6, Abt. 3b, p. 24. Leipzig.

9. Humphrey, L. M. 1932. The chromosomes of Lycopersicum pimpinellifolium. Am. J. Bot. $19: 812-813$.

10. - 1934. The meiotic divisions of haploid, diploid and tetraploid tomatoes with special reference to the prophase. Cytologia 5: 278-300.

11. Lawrence, W. J. C. 1931. The secondary association of chromosomes. Cytologia $2: 352-384$.

12. Lesley, M. M. 1926. Maturation in diploid and triploid tomatoes. Genetics 11: 207-279.

13. Lindstrom, E. W. 1935. Segregation of quantitative genes in tetraploid tomato hybrids as evidence for dominance relations of size characters. Genetics $20: 1-11$.

14. - and Koos, K. 1931. Cytogenetic investigations of a triploid tomato and its diploid and tetraploid progeny. Am. Jour. Bot. 18: 398-410.

15. - and Humphrey, L. M. 1933. Comparative cytogenetic studies of tetraploid tomatoes from different sources. Genetics $18: 193-204$.

16. Miller, P. 1788 . Dictionaire des Jardiniers. $4: 486-494$. Bruxelles.

17. Sax, K. and Humphrey, L. M. 1934. Structure of meiotic chromosomes in microsporogenesis of Tradescantia. Bot. Gaz. $96: 353-362$.

18. Winkler, H. 1916. Über die experimentelle Erzeugung von Pflanzen mit abweichenden Chromosomenzahlen. Zeits. f. Bot. 8: 417-531. 